\title{
ADMINISTRACIÓN MANCOMUNADA Y CONVOCATORIA DE LA JUNTA: ¿DIMENSIÓN ESTRICTAMENTE INTERNA?
}

Carlos Soler Samper

Profesor Asociado de Derecho Mercantil

Departamento de Ciencia Jurídica

Área de Derecho Mercantil Universidad Miguel Hernández 
El pasado mes de julio el Tribunal Supremo sentó precedente en uno de los aspectos societarios más controvertidos, tal y como es

la administración mancomunada y la convocatoria de junta, a través de su sentencia de 16 de julio de 2019, n 424/2019 (Rec. n' 3784/2016).

\section{Hechos y decisión del Tribunal Supremo.}

En cuanto a los hechos del supuesto concreto, nos encontramos en una sociedad limitada, cuyo órgano de administración está compuesto por cuatro miembros, siendo los mismos, a su vez, socios de la entidad junto al socio recurrente. De tal forma que el capital social se divide entre cinco socios (cuatro socios-administradores y un socio-no administrador). Asimismo, cabe recalcar que los administradores ejercen sus potestades de manera mancomunada.

Una vez reflejada la estructura interna, atenderemos a los hechos objeto del litigio. Las circunstancias originarias de la controversia consisten en las convocatorias de dos juntas generales, que fueron llevadas a cabo, respectivamente, por una parte de los administradores mancomunados: la primera de ellas fue convocada por dos de los cuatro administradores, mientras que la segunda fue convocada por tres de ellos.

A pesar de que dichas juntas no fueron convocadas por la totalidad de los administradores mancomunados, como en teoría debería realizarse según el carácter propio de la mancomunidad, los mismos asistieron a dichas reuniones, siendo el quinto socio de la entidad el único de ellos que no asistió a las reuniones. Cabe resaltar también que las notificaciones de dichas convocatorias se realizaron correctamente $\mathrm{y}$ de acuerdo a las formalidades exigidas.

Según el quinto socio no administrador, las juntas no fueron válidamente convocadas, al no efectuarse por la totalidad de los administradores mancomunados, por lo que el mismo procedió a impugnar los acuerdos sociales aprobados en ambas, solicitando la correspondiente nulidad de las mismas. Esta postura del socio disidente fue rechazada en las dos primeras instancias $y$, finalmente, en la presente sentencia del Tribunal Supremo.

Asimismo, el fundamento base del Tribunal Supremo consiste, tal y como dice en la sentencia objeto de comentario, en la "disociación entre la titularidad del poder de representación, que depende de lo dispuesto en los estatutos y se sujeta a las reglas del artículo 232.2 de la Ley de Sociedades de Capital, y el poder de gestión, que corresponde al conjunto de administradores mancomunados y que, por tanto, habrá de ejercitarse por todos ellos de forma conjunta (art. 210 LSC)".

Dicho esto, el Tribunal considera que el requisito de unanimidad en las decisiones que afectan al poder de gestión puede ocasionar una situación de bloqueo o "parálisis de la sociedad" y, dado que la competencia de convocatoria de la junta general se encuadra en el poder de gestión o administración de los administradores, la misma "tiene una dimensión estrictamente interna" $y$, por ende, "no son aplicables las reglas sobre el poder de representación", que ostentan una dimensión externa.

De lo anteriormente expuesto, el Tribunal finaliza resolviendo en contra del socio impugnante, al considerar que no es necesaria la convocatoria efectuada por la totalidad de los administradores mancomunados en tanto que, si atendemos a las circunstancias del caso, en el que la totalidad de los mismos acuden a dichas juntas, dicha formalidad podría obstaculizar la marcha de la sociedad y dañar el interés social de la misma, por lo que las juntas y los acuerdos adoptados en las mismas 
son válidos.

A raíz de los hechos y razonamientos anteriormente expuestos, resulta inevitable pensar que la potestad decisoria del Alto Tribunal puede resultar conflictiva $y$, en ocasiones, errática, en tanto que el pronunciamiento del Tribunal Supremo va totalmente en contra de la propia naturaleza de la mancomunidad y, por ende, de las reglas de la sociedad, cuyos estatutos sociales prevén dicha modalidad de organización y decisión.

$Y$ es que si la sociedad ha decidido regirse por dichos parámetros de la mancomunidad, con sus requisitos y formalidades, resulta incongruente que el Tribunal Supremo decida romper con la naturaleza de dicha modalidad, beneficiando sólo a una parte de su capital social, sin importar que fue la totalidad del mismo la que decidió regirse por una concretas normas societarias en relación con determinadas circunstancias o características internas (posiblemente conflictivas) que, con relación a lo expuesto, pueden cobrar más sentido si cabe.

\section{II.- Pronunciamientos precedentes de debate.}

Resulta interesante resaltar que, en la propia sentencia, el Tribunal Supremo hace mención a la Resolución de la Dirección General de los Registros y del Notariado, con fecha 4 de mayo de 2016, en la que se estableció, como otras resoluciones anteriores, que "la mancomunidad parcial se prevé legalmente solo respecto de la representación, pero no en cuanto a la gestión, salvo que los estatutos establezcan que los administradores con poder mancomunado pueden gestionar de forma solidaria los asuntos internos de la compañía". Es decir, según esta Resolución de la DGRN, el requisito de unanimidad de convocatoria por parte de los administradores mancomunados, que se establece legalmente, se puede excepcionar en el caso de que se prevea dicha posibilidad en los estatutos sociales de la entidad. Lo que, hasta ahora, establecía la doctrina de la DGRN consistía en que la convocatoria de la Junta realizada por dos de los tres administradores mancomunados no era válida, pero sí tenían el poder de representación frente a terceros, tal y como establece el artículo 233.2.c) de la Ley de Sociedades de Capital. Es decir, estamos hablando de casos en los que los Estatutos Sociales de la sociedad se limitan a indicar que el poder de representación corresponde a un número determinado de los administradores mancomunados, pero sin precisar en la facultad interna relativa a la convocatoria de la Junta.

Volviendo al presente supuesto, el Tribunal Supremo prosigue justificando su postura en que, debido a las circunstancias del caso concreto en que tanto los administradores convocantes como los no convocantes asistieron a las juntas generales sin hacer objeción alguna ni a su convocatoria ni a su contenido, se debe velar por el interés social, al constituir, dicha asistencia, un acto de conformidad tácita a las celebraciones de las juntas. Pero lo realmente preocupante es la situación e incertidumbre del socio impugnante, porque, en caso de que no se prevea la situación de excepción mencionada en la Resolución mencionada de la DGRN y no se respeten las propias reglas de la sociedad ¿qué debemos hacer? ¿dejar que se celebren juntas y se adopten acuerdos sin respetar las normas y formalidades de convocatoria internas? ¿asistir a dichas juntas convocadas de manera contraria a los preceptos societarios de la entidad concreta? ¿debe primer el interés social subjetivo o las normas internas de la sociedad?

Como se puede observar, la sentencia del Tribunal Supremo da un giro de gran relevancia en cuanto a las relaciones societarias internas y al especial cuidado que se debe prestar en cuanto 
a la regulación de las facultades de los administradores mancomunados y sus limitaciones a la hora de llevar a cabo las actividades internas societarias, ya que puede tener efectos de especial índole en otras ramas mercantilistas internas, tales como la concursal, ya que el efecto de la interpretación abierta o preventiva de obstáculos de decisiones societarias se puede trasladar perfectamente al ámbito externo causando una inseguridad jurídica sin precedentes.

El presente asunto ya ha sido objeto de estudio por algunos autores tales como Virginia Vega

Clemente o Marcial Herrero Jiménez, quienes abordan la temática afirmando que, tal y como establece la jurisprudencia, no existía confusión en que, para la convocatoria efectuada por un órgano de administración mancomunado, se precisa la participación de todos ellos en la misma y, a su vez, expresan que "la convocatoria de la Junta general de la sociedad mercantil debe reunir unos requisitos formales y materiales que garanticen los derechos de los socios. El principio de seguridad jurídica exige la observancia de estos requisitos, protegiendo así los intereses de los socios". A pesar de ello, los mismos también exponen, basándose en la sentencia de la Audiencia Provincial de Cantabria, de 4 de junio de 2013 (recurso 653/2012), que "cabría subsanar dicho defecto mediante la asistencia a la Junta General del resto de administradores mancomunados que no se opongan a la válida celebración de la misma". Eso sí, creemos que se debe atender a las circunstancias del caso concreto y, como se puede apreciar, en ningún caso se habla de pronunciamientos por parte del Tribunal Supremo al respecto.

Por otro lado, dicho ámbito externo que el Tribunal Supremo presenta como inequívoco en la presente sentencia se cuestiona, sin embargo, en su sentencia de 17 de noviembre de 2010 (Rec. 642/2007), en la que una sociedad limitada, como compradora, interpuso demanda so- licitando que se declarara la existencia y validez de un contrato de compraventa de un inmueble frente a la vendedora demandada, e instó su cumplimiento.

La parte vendedora alegó "defecto de capacidad procesal insubsanable y falta de legitimación activa" porque el contrato de compraventa se había suscrito solo por uno de los dos administradores mancomunados de la sociedad demandante, aunque -según los estatutos de la sociedad demandante- era necesaria la intervención y firma de ambos administradores mancomunados para cualquier actuación.

El Tribunal Supremo decidió en favor de la parte compradora al considerar la "aceptación tácita" del administrador no firmante a través de la interposición de la demanda, ya que la misma precisa, para su presentación, la aceptación y los correspondientes poderes de representación de ambos al letrado representante.

\section{III.- Posible repercusión normativa y jurisprudencial.}

Tal y como establece la propia LSC en su artículo 249.bis. j), la convocatoria de Junta consiste en una de las facultades primordiales e indelegables del Consejo de Administración, que sólo acepta, a priori, determinadas excepciones, tales como las expuestas en el artículo 171 del mismo texto legal, en el que la legitimación para solicitar la convocatoria de la junta se puede conceder, de manera excepcional, a cualquier socio en caso de muerte o de cese del administrador único, de todos los administradores o de alguno de los administradores mancomunados siempre que no existan suplentes, pero, como bien indica Alberto Emparanza Sobejano, "se trata de casos en los que el órgano de administración no se encuentre conformado adecuadamente, impidiéndose así que pueda actuar, bien porque 
hayan fallecido, dimitido o cesado sus administradores, bien porque, por las causas que sea, no está en condiciones de funcionar [...]."

En relación con dicho artículo 171 LSC, debemos prestar especial cuidado, a su vez, y en cuanto al posible desarrollo jurisprudencial al respecto que se podrá producir de ahora en adelante, a lo establecido en el artículo en el artículo 204.3 a) TRLSC y la impugnación de acuerdos:

3. Tampoco procederá la impugnación de acuerdos basada en los siguientes motivos:

a) La infracción de requisitos meramente procedimentales establecidos por la Ley, los estatutos o los reglamentos de la junta y del consejo, para la convocatoria o la constitución del órgano o para la adopción del acuerdo, salvo que se trate de una infracción relativa a la forma y plazo previo de la convocatoria, a las reglas esenciales de constitución del órgano o a las mayorías necesarias para la adopción de los acuerdos, así como cualquier otra que tenga carácter relevante."

De acuerdo a esta disposición, se podría limitar perfectamente, aún más si cabe, la posibilidad de impugnación de acuerdos sociales con una convocatoria de Junta que no se ha realizado de acuerdo a las correspondientes disposiciones legales o estatutarias. Al respecto se ha pronunciado autores como María Ángeles Alcalá

Díaz o María Jesús Blanco Sánchez, quienes indican que "la redacción del precepto no es la más adecuada [...]" "en el sentido de construirse como una "excepción a la excepción" y requerir de aplicación sistemática, que llevaría a concluir que son acuerdos impugnables los afectados por infracciones procedimentales que la ley considera relevantes en todo caso y que son las relativas a la forma y el plazo previo de la convocatoria. En tanto se establece como presunción, el demandante no tendrá que acreditar la gravedad de la infracción, sino que corresponderá a la sociedad probar su irrelevancia."
Eso sí, como también indica Fernando Ruíz Vives, "Los acuerdos afectados por infracciones procesales distintas de las mencionadas en la norma no entrarían dentro de la presunción legal establecida por la norma. Serían las infracciones relativas a cualquiera de las fases del proceso que culmina con la proclamación del resultado de la junta: convocatoria, constitución y adopción de acuerdos. En estos casos será la parte demandante quien deba acreditar la relevancia del defecto."

Como se observa en el presente caso, dicha "relevancia del defecto", en cuanto a la convocatoria de la Junta, se podría ver eclipsada por la posible futura línea jurisprudencial del Supremo.

A pesar de ello, existen autores que comparten una visión totalmente distinta a la expuesta en el presente artículo, llegando a defender, tal y como refleja el Alto Tribunal en su sentencia de 19 de julio de 2019, que el requisito de convocatoria de junta llevada a cabo por la totalidad de los administradores mancomunados podría generar actuaciones torticeras o de bloqueo societario, queriendo evitar, con ello, actitudes contrarias a la buena fe, como sería el caso en el que, tal y como expone Jesús Alfaro Águila-Real, un socio minoritario quisiera evitar ser destituido como administrador $y$, además, que se modifique el modo de administración mediante el correspondiente acuerdo de la Junta. Pues bien, como él expone, esta situación podría "entorpecer tal destitución, simplemente, negando su concurso a la convocatoria de la junta," de modo que llega a afirmar que, como la convocatoria de junta es un acto de gestión del contrato social, en caso de que se produjese una convocatoria incompleta "el administrador que convoque la Junta a espaldas de los demás administradores, habrá incumplido sus deberes, pero la convocatoria ha de considerarse válida".

A raíz de todo lo anteriormente expuesto, 
podemos extraer la idea de que, efectivamente, cualquier situación que pudiese producir un constante bloqueo societario y, por ende, de actuaciones o decisiones, debe poder solucionarse a través de la vía más amistosa y beneficiosa para la actividad y estabilidad de la sociedad. Sin embargo, no por ello debemos caer en el error de querer contradecir la propia voluntad social, establecida normalmente en los estatutos, y en la inseguridad jurídica total, ya que es una obligación de los tribunales interpretar las normas legales y estatutarias, tal y como se refleja en el propio Código Civil, en su artículo 3, "según el sentido propio de sus palabras, en relación con el contexto, los antecedentes históricos y legislativos, y la realidad social del tiempo en que han de ser aplicadas, atendiendo fundamentalmente al espíritu y finalidad de aquellas." En atención a todo ello, el hecho de que uno o varios socios se puedan ver indefensos, tal y como se refleja en los hechos de la sentencia del Tribunal Supremo, es motivo más que suficiente para poder replantear las inequívocas decisiones del Alto Tribunal, así como una posible reforma de los principios reguladores de la propia figura de la administración mancomunada en las sociedades de capital. 


\section{Bibliografía}

ALCALÁ DÍAZ, M.A., "La delimitación de los supuestos de infracción de requisitos procedimentales en los que se excluye la impugnabilidad de los acuerdos sociales [art. 204.3.a.) LSC]", en AA.VV. Estudio de las modificaciones de la Ley de Sociedades de Capital introducidas por las Leyes 31/2014, de 3 de diciembre, 5/2015, de 27 de abril, 9/2015, de 25 de mayo, 15/2015, de 2 de julio y 22/2015, de 20 de julio, así como de las Recomendaciones, Aranzadi, 2016, pp. 331-383.

ALFARO ÁGUILA-REAL, J. “Ejercicio de la actividad de administración y ejercicio del poder de representación", Almacén de Derecho, 8 de enero de 2016.

BLANCO SÁNCHEZ, M.J., "Convocatoria de Junta General y medios de comunicación electrónicos.

Exigencia de denuncia previa de los defectos de forma para la impugnación de acuerdos", en Derecho de Sociedades. Cuestiones sobre órganos sociales, Tirant lo Blanch, 2018.

EMPARANZA SOBEJANO, A. “La junta general. La junta registral. La junta judicial”, en Tratado de conflictos societarios, Tirant lo Blanch, 2019.

HERRERO JIMÉNEZ, M., y VEGA CLEMENTE, V. “La nulidad de la convocatoria de junta general como consecuencia de la vulneración del derecho de información del socio y otros defectos formales", en Derecho de sociedades. Cuestiones sobre órganos sociales. Tirant lo Blanch, 2018.

VIVES RUIZ, F., "Impugnación de acuerdos sociales. Defectos procedimentales relevantes: delimitación y legitimación para impugnar", Revista de Derecho Bancario y Bursátil, núm. 147, 2017, pp. 29-108.

\section{Pronunciamientos de tribunales}

Sentencia civil No 424/2019, Tribunal Supremo, Sala de lo Civil, Sección 1, Rec 3784/2016 de 16 de Julio de 2019.

Sentencia civil, No 774/2010, Tribunal Supremo, Sala de lo Civil, Sección 1, Rec 642/2007 de 17 de noviembre de 2010.

Sentencia Audiencia Provincial de Cantabria, de 4 de junio de 2013, Rec. 653/2012).

Resolución de la Dirección General de los Registros y del Notariado, con fecha 4 de mayo de 2016. 
